origin and relatively simple etiology, is not affected by the method of treatment.

There is every evidence in this book of great care in preparation. This is seen in the accurate use of terms, in the clear and simple style of writing, and in the freedom from mistakes. The matter is presented in a manner relevant to the needs of foresters, who as a rule are laymen in pathology. If this not infrequently results in a collection of interesting information about a fungus which it would be difficult to identify from the text, recourse can always be had to papers cited. In this way is solved the difficulty of catering both for the forestry student, who must needs learn some pathology for his examination, and for the serious student of the subject, who requires more detailed information. Prof. Boyce is to be congratulated on the successful completion of a difficult task, and English-speaking foresters on the receipt of a book of real value and service.
W. R. DAY.

\title{
Chemical Analysis
}

(I) Gas Analysis

By A. McCulloch. Pp. 166. (London: H. F. and G. Witherby, Ltd., 1938.) 7s. $6 d$. net.

\section{(2) Micromethods of Quantitative Organic} Elementary Analysis

By Prof. Joseph B. Niederl and Victor Niederl. Pp. xvi +271. (New York: John Wiley and Sons, Inc. ; London : Chapman and Hall, Ltd., 1938.) 15s. net.

(3) Tables of Reagents for Inorganic Analysis : First Report of the International Committee on New Analytical Reactions and Reagents of the Union internationale de Chimie. By C. J. van Nieuwenburg, W. Böttger, F. Feigl, A. S. Komarovsky, N. Strafford. Pp. xxiv +409. (Leipzig : Akademische Verlagsgesellschaft m.b.H., 1938.) 36 gold marks.

IN these days of extreme specialization, it can searcely be expected that the basic subject of analytical methods will escape selective treatment. The trend is manifest in the preparation and publication of small text-books in which the methods applicable to the practice of a particular industry are selected: these probably save a good deal of time to workers in the special subjects, and to students taking limited laboratory courses in which the practice, rather than the art, of chemistry is demonstrated.

(1) A good example of such books is that on gas analysis, a subject which is much to the fore both in connexion with fuel technology, the science which is enabling one ton of coal to be burnt where three tons were necessary before its application, and in relation to syntheses from elementary gases in presence of catalysts. It covers the field satisfactorily without going into great detail; the more complex apparatus for analysing mixtures of hydrocarbons is omitted.

(2) Quite another field is the micro-analysis of organic substances which has rendered it possible for the research worker, particularly in the biochernical field, to make astounding progress with quite small quantities of material. Pregl, in Vienna, made the start in this work ; his methods have since been copied, adapted, and improved in many centres. The latest book comes from the New York University in Washington Square, and describes and figures the apparatus required, and how to use it. In large research laboratories it is becoming usual, and, indeed, necessary, to set aside a special room for this purpose staffed by competent assistants, who give their whole time to the work. It is good news to hear that there is about to be such a laboratory at the Imperial College, South Kensington.

(3) A third line of development worthy of emphasis is that of reagents. During the last decade the technique of qualitative analysis has been facilitated by the use of an exceptionally large number of new reagents, many of them organic compounds. The Union Internationale de Chimie has set up a Committee of five to report on new analytical reagents and reactions, on which Mr. N. Strafford, of Manchester, represents Great Britain; the report takes the form of a book largely in tabular form, in three languages, an achievement which is in itself substantial.

There are so many new reagents that teachers are faced with problems regarding their suitability which they lack the time to investigate. The report aims at giving help to this end, and contains full information, with references to all the reagents discovered in the period 1910-36. Some of them bear the indication "recomm."

Such a book was badly needed, and will no doubt find shelf room in every laboratory. It is printed and published in Germany.

It is pleasing to have this result of international co-operation, and it may be hoped that, in future, these congresses will more and more have the effect of getting the chemists of the nations to work together to similar ends. 